\title{
Development of irreversible airflow obstruction in a patient with eosinophilic bronchitis without asthma
}

\author{
C.E. Brightling, G. Woltmann, A.J. Wardlaw, I.D. Pavord
}

\begin{abstract}
Development of irreversible airflow obstruction in a patient with eosinophilic bronchitis without asthma. C.E. Brightling, G. Woltmann, A.J. Wardlaw, I.D. Pavord. (C) ERS Journals Ltd 1999.

ABSTRACT: Eosinophilic bronchitis is a recently described condition presenting with chronic cough and sputum eosinophilia without the abnormalities of airway function seen in asthma. The patient, a 48-yr-old male who had never smoked, presented with an isolated chronic cough. He had normal spirometric values, peak flow variability and airway responsiveness, but an induced sputum eosinophil count of $33 \%$ (normal $<1 \%$ ). Although his cough improved with inhaled corticosteroids the sputum eosinophilia persisted. Over 2 yrs he developed airflow obstruction, which did not improve following nebulized bronchodilators and a 2-week course of prednisolone 30 mg once daily sufficient to return the sputum esinophilia to normal $(0.5 \%)$. It is suggested that the progressive irreversible airflow obstruction was due to persistent structural change to the airway secondary to esinophilic airway inflammation, and it is further speculated that eosinophilic bronchitis may be a prelude to chronic obstructive pulmonary disease in some patients.
\end{abstract}

Eur Respir J 1999; 14: 1228-1230.

Dept of Respiratory Medicine, The
Glenfield Hospital, Leicester, UK.

Correspondence: I.D. Pavord Department of Respiratory Medicine The Glenfield Hospital Groby Road Leicester LE3 9QP UK Fax: 441162367768

Keywords: Chronic obstructive pulmonary disease

eoisnophilic bronchitis

Received: November 231998

Accepted after revision April 141999
Recently GIBSON and co-workers [1, 2] described a group of patients with chronic cough who had sputum evidence of an eosinophilic bronchitis but normal spirometry, no evidence of airway hyperresponsiveness and normal peak expiratory flow (PEF) variability. The features of this condition were distinct from asthma and they suggested it should be known as eosinophilic bronchitis. Eosinophilic bronchitis has been shown to be present in $10-15 \%$ of patients with isolated chronic cough referred to a respiratory specialist $[3$, 4]. The underlying pathology of this condition and its natural history is unknown. This report describes a case of a patient with eosinophilic bronchitis who developed progressive irreversible airflow obstruction

\section{Case report}

A 48-yr-old policeman was referred in September 1996 by his general practitioner with a 2 -yr history of cough, which produced small amounts of mucoid sputum. The cough was worse in the morning and was associated with a sensation of being unable to clear his throat. He described the cough as mild but persistent, and that it had worsened over the previous few months. He had no dyspnoea or wheeze and had no symptoms to suggest rhinitis or gastrooesophageal reflux. Previously he had been very fit and well with no previous respiratory problems and no eczema or hayfever. He has never smoked and kept no pets. His symptoms were unrelated in time to work and he was not exposed to any known sensitizing agents. His clinical examination and a chest radiograph were normal. Initial spirometry was within normal limits; forced expiratory volume in one second (FEV1) $3.87 \mathrm{~L}$ (98\% of predicted), and FEV1/forced vital capacity (FVC) ratio $82 \%$. Skin prick tests with extracts from common allergens resulted in a 2-mm and a 3-mm wheal in response to dog and cat fur, respectively. Serum total immunoglobulin (Ig)E was normal and his blood eosinophil count was the upper limit of normal at $0.38 \times 10^{9}$ cells $\cdot \mathrm{L}^{-1}(0.06-0.40)$. Serology for parasites was normal. His $\alpha_{1}$-antitrypsin level was $1.3 \mathrm{~g} \cdot \mathrm{L}^{-1}$ (normal range $1.1-2.4 \mathrm{~g} \cdot \mathrm{L}^{-1}$ ) with a homozygous MM genotype pattern. His only medication was inhaled beclomethasone $200 \mu \mathrm{g}$ b.i.d., which he had been taking for 3 months without clinical improvement.

Inhaled steroids were stopped so that a clear diagnosis could be established. Twice daily PEF monitoring, over 1 month, revealed normal within day variability and formal pulmonary function tests were normal. Methacholine airway responsiveness was normal (provocative concentration causing a $20 \%$ fall in FEV1 $\left(\right.$ PC20) $\left.>16 \mathrm{mg} \cdot \mathrm{mL}^{-1}\right)$. An induced sputum sample obtained by inhalation of nebulized hypertonic saline and processed using a standardized protocol $[5,6]$ revealed a marked eosinophilia (33\%; normal range $0-1 \%)$. The details of the sputum content are shown in table 1 . To exclude possible contamination of sputum samples from concomitant upper airway inflammation, nasal lavage was processed in the same fashion and demonstrated no evidence of upper airway eosinophilic inflammation. Likewise, upper airway responsiveness to histamine was normal (provocative concentration of histamine causing a $25 \%$ fall in mid inspiratory flow $>16 \mathrm{mg} \cdot \mathrm{mL}^{-1}$ ) [7]. A diagnosis of eosinophilic bronchitis was made and the patient was started on inhaled budesonide $200 \mu \mathrm{g}$ b.i.d. via a turbohaler (pulmicort; Astra Pharmaceuticals, Kings Langley, UK). Inhaled corticosteroids were continued for 25 months at a daily dose of 400$800 \mu \mathrm{g}$, apart from a 4-week period in September 1997 (fig. 1). His cough improved although the sputum eosinophil count measured at intervals remained elevated between 2.8 and $75 \%$. Methacholine and histamine airway responsiveness was measured on four further occasions and remained normal. PEF monitoring showed normal within day variability 
Table 1. - Sputum characteristics over a 25-month period

\begin{tabular}{|c|c|c|c|c|c|c|c|c|c|c|}
\hline & \multicolumn{10}{|c|}{ Month } \\
\hline & 1 & 2 & 3 & 7 & 10 & 12 & 13 & 21 & 22 & 25 \\
\hline Weight selected sputum mg & 151 & 338 & 99 & 315 & 445 & 1140 & 576 & 216 & 108 & 157 \\
\hline Total cell count $\times 10^{6}$ cells.mg sputum ${ }^{-1}$ & 1.1 & 1.84 & 1.46 & 2.32 & 2.53 & 1.49 & 1.1 & 1.86 & 0.94 & 0.99 \\
\hline Viability \% & 89 & 78 & 40 & 65 & 69 & 72 & 16 & 76 & 58 & 28 \\
\hline Squamous cell contamination $\%$ & 1 & 1.3 & 2 & 0.8 & 6.5 & 8 & 1 & 1 & 3 & 4.3 \\
\hline Neutrophils \% & 56 & 43.4 & 60.4 & 73 & 31.4 & 18 & 36 & 38.4 & 42.6 & 19.8 \\
\hline Eosinophils \% & 33 & 49.5 & 20.4 & 13.4 & 5.9 & 75 & 48 & 2.8 & 0.5 & 13.2 \\
\hline Macrophages \% & 9 & 6.1 & 18.7 & 12.2 & 61.7 & 7 & 7 & 55.4 & 53.9 & 55.9 \\
\hline Epithelial cells \% & 2 & 0 & 0.4 & 0.8 & 0 & 0 & 8 & 3.4 & 2 & 10.2 \\
\hline Lymphocytes \% & 0 & 0 & 0 & 0.6 & 1 & 0 & 1 & 0 & 1 & 0.9 \\
\hline
\end{tabular}

over three separate months. However, serial measurements of FEV1 showed a progressive decline over this period (fig. 1), such that in July 1998, FEV1 was $3.1 \mathrm{~L}$ (79\% pred) and the FEV1/FVC ratio $70 \%$. Following a 2 -week course of prednisolone $30 \mathrm{mg}$ daily, there was complete resolution of the cough and sputum eosinophilia $(0.5 \%)$, but no change in spirometric values (FEV1 $3.0 \mathrm{~L}, 76 \%$ pred; FEV1/FVC ratio $68 \%$ ). Methacholine airway responsiveness remained normal in the presence of airflow obstruction. Repeat spirometry and induced sputum in October 1998, whilst still on inhaled steroids again showed irreversible airflow obstruction (FEV1 $3.15 \mathrm{~L}, \mathrm{FEV} 1 / \mathrm{FVC}$ ratio 69\%). There was no significant response to $2.5 \mathrm{mg}$ nebulized salbutamol (FEV1 3.3, FEV1/ FVC ratio $70 \%$ ). On this occasion his sputum eosinophil count had risen to $13.1 \%$ and his cough was well controlled. A bronchoscopy was performed, which demonstrated macroscopically normal airways. Bronchial wash confirmed a significant eosinophilia of $12.9 \%$. A high resolution computerized tomograph (HRCT) of the thorax revealed no abnormalities in either inspiratory or expiratory films.

\section{Discussion}

The patient presented with a cough and sputum eosinophilia, but without the variable airflow obstruction or airway hyperresponsiveness characteristic of asthma [8]. These features are typical of eosinophilic bronchitis as described by GIBSON and co-workers [1,2], which has since been shown to be a common cause of chronic cough [4]. In agreement with previously described cases, the cough improved with inhaled corticosteroids [1, 2], but in the current case, the sputum eosinophil count remained grossly elevated. The main point of interest was the progressive development of irreversible airflow obstruction in association with persistent airway eosinophilia. The airflow obstruction did not respond to nebulized $\beta_{2}$-agonist or a course of prednisolone, sufficient to eliminate sputum eosinophilia, suggesting it was not due to bronchospasm or directly due to airway inflammation. A more likely explanation for the development of airflow obstruction is persistent structural change to the airway secondary to inflammation. The HRCT scan did not reveal any abnormalities in either inspiration or expiration to support
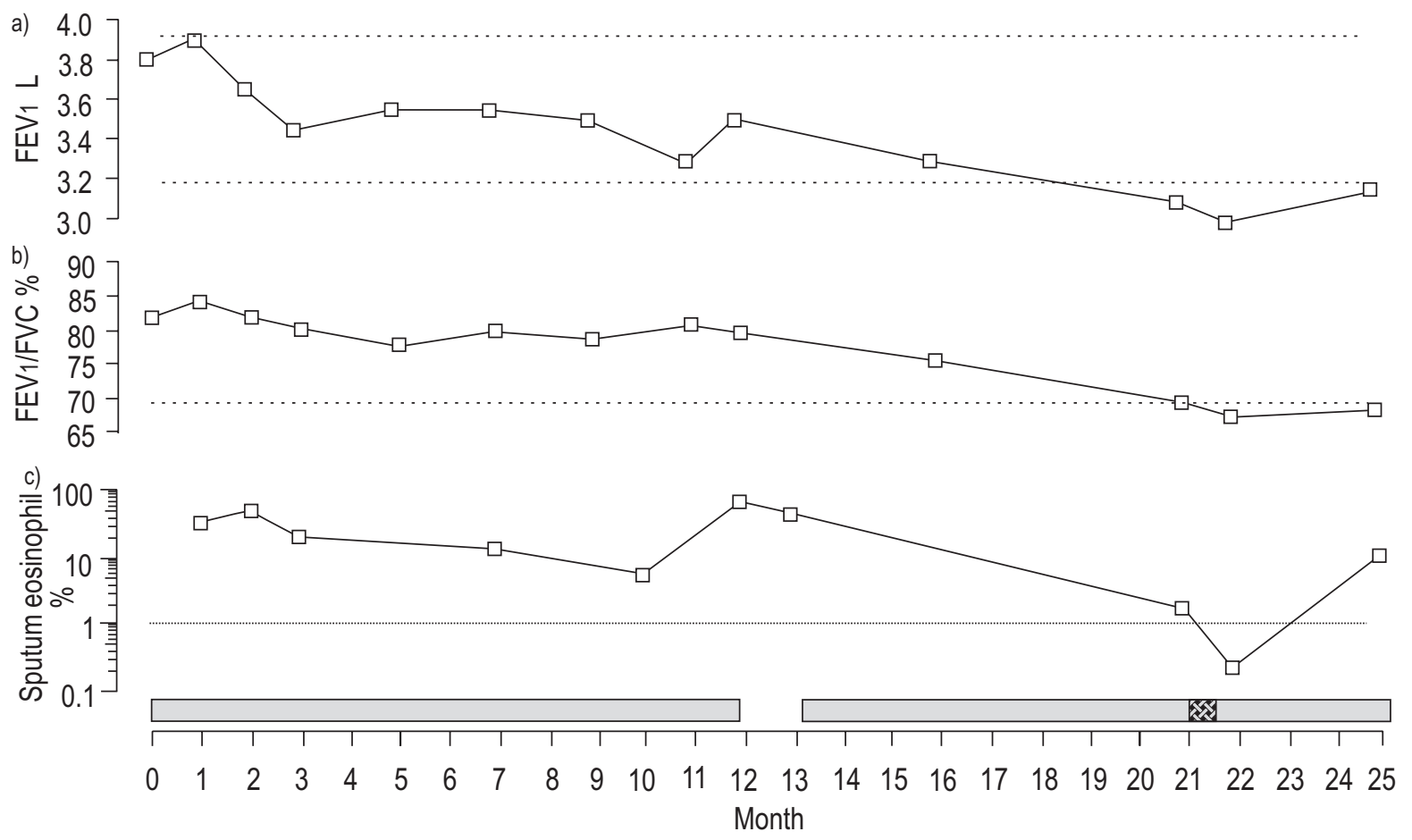

Fig. 1. - Changes in a) forced expiratory volume in one second (FEV1), b) FEV1/forced vital capacity (FVC) ratio, and c) sputum eosinophil count over 25 months. a) - . - : maximum and $80 \%$ predicted FEV 1 ; b) - . . : 70\% FEV1/FVC; c) . . . . . : upper limit of normal range $(0-1 \%)$ of sputum eosinophil count. $\square$ : treatment with inhaled corticosteroids; : treatment with oral prednisolone $30 \mathrm{mg}$ once daily. 
this, but it is expected that this was due to the changes being too subtle to demonstrate with imaging.

Some patients with chronic obstructive pulmonary disease (COPD) have sputum or bronchoscopic evidence of an airway eosinophilia often attributed to an asthmatic component of their airway disease $[9,10]$. The current case demonstrates that fixed airflow obstruction can occur in the presence of eosinophilic inflammation without previous asthma and raises the possibility that some patients with eosinophilic bronchitis may develop COPD. If this is true, it has important implications in the early diagnosis and successful treatment of eosinophilic bronchitis.

Traditionally, the success of a treatment for chronic cough is determined by the clinical response. The patient had good symptomatic improvement on moderate doses of inhaled corticosteroids. In spite of his good symptom control, the patient still had underlying eosinophilic inflammation. This raises the question of whether therapy should be directed towards controlling the airway inflammation as well as symptoms. As a result, the patients' maintenance inhaled corticosteroids have been increased to try to achieve this.

The aetiology of the eosinophilic airway inflammation in the patient is unclear. The mechanisms involved in the development of airway inflammation may be similar to asthma. Although the patient was atopic, atopy has not been found to be a consistent feature of patients with eosinophilic bronchitis [4]. Acrylates have been shown to cause an occupational eosinophilic bronchitis [11]. Fingerprinting techniques involve exposure to acrylates, but the present patient had not performed this task for several years. In the absence of a significant peripheral blood eosinophilia, raised total $\mathrm{IgE}$, positive parasite serology and changes on chest imaging, a form of pulmonary eosinophilia is excluded.

Another interesting feature of this case is that a sputum eosinophilia can occur in patients without the variable airflow obstruction or airway hyperresponsiveness typical of asthma. Possible explanations for the different functional consequences of the eosinophilic airway inflammation in the patient include differences in the site or state of activation of the inflammation. A predominant upper airway inflammatory response is unlikely since eosinophils were not seen in the nasal wash, there was no upper airway hyperresponsiveness and eosinophils were present in the bronchial wash. A more likely explanation is that the inflammatory response is mainly localized to the small airways. The development of fixed airflow obstruction in the present case would then have parallels with the neutrophilic bronchiolitis seen in smokers with COPD. A predominant small airway inflammatory response also offers a possible explanation for the poor response to inhaled corticosteroids. An alternative possibility is that airway responsiveness is increased by the airway inflammation in eosinophilic bronchitis, but stays within the normal range because baseline airway responsiveness is far to the right of the normal range. Such a phenomenon has recently been observed in a patient with eosinophilic bronchitis studied during an exacerbation of eosinophilic airway inflammation [12].

The rapidity of the fall in FEV1 in this patient is puzzling, although it is assumed it is related to the severity of the underlying airway inflammation. COPD is thought to be the result of moderately accelerated decline in FEV1 over many years. The patient showed a different pattern, with a rapid fall in FEV1 occurring after a period of several years when he had symptoms, but normal spirometric values. This pattern would fit well with predominant small airway inflammation, since the small airways contribute little to the overall respiratory resistance until extensively damaged.

In conclusion, this case report demonstrates an association between eosinophilic bronchitis without asthma and the development of irreversible airflow obstruction. It raises the possibility of eosinophilic bronchitis as a cause of some cases of chronic obstructive pulmonary disease and highlights the importance of diagnosing eosinophilic bronchitis and the use of sputum induction in a clinical setting. Further research into the nature, site and state of activation of the eosinophilic airway inflammation in patients such as this might identify particular features of the inflammatory response that have different functional consequences.

\section{References}

1. Gibson PG, Dolovich J, Denburg J, Ramsdale EH, Hargreave FE. Chronic cough: eosinophilic bronchitis without asthma. Lancet 1989; i: 1346-1348.

2. Gibson PG, Hargreave FE, Girgis-Gabardo A, Morris M, Denburg JA, Dolovich J. Chronic cough with eosinophilic bronchitis: examination for variable airflow obstruction and response to corticosteroid. Clin Exp Allergy 1995; 25: 127132.

3. Carney IK, Gibson PG, Murnee-Allen K, Saltos N, Olsen LG, Hensley MJ. A systematic evaluation of mechanisms in chronic cough. Am J Respir Crit Care Med 1997; 156: $211-$ 216.

4. Brightling CE, Ward R, Goh KL, Wardlaw AJ, Pavord ID. Eosinophilic bronchitis is an important cause of cough. Am J Respir Crit Care Med 1999; 160: 406-410.

5. Pavord ID, Pizzichini MMM, Pizzichini E, Hargreave FE. The use of induced sputum to investigate airway inflammation. Thorax 1997; 52: 498-501.

6. Pizzichini E, Pizzichini MMM, Efthimiadis A, et al. Indices of airway inflammation in induced sputum: reproducibility and validity of cell and fluid phase measurements. $A m J$ Respir Crit Care Med 1996; 154: 308-317.

7. Bucca C, Rolla G, Scappaticci E, et al. Extrathoracic and intrathoracic airway responsiveness in sinusitis. $J$ Allergy Clin Immunol 1995; 95: 52-59.

8. Taylor DR. Making the diagnosis of asthma. BMJ 1997; 315: 4-5.

9. Pavord ID, Pizzichini MMM, Pizzichini E, Hargreave FE. Eosinophilic bronchitis with fixed airflow obstruction. $\mathrm{Am} \mathrm{J}$ Respir Crit Care Med 1998; 157: A624.

10. Chanez P, Vignola AM, O'Shaugnessy T, Enander I, Li D, Jeffrey P, Bousquet J. Corticosteroid reversibility in COPD is related to features of asthma. Am J Respir Crit Care Med 1997; 155: 1529-1534.

11. Lemière $\mathrm{C}$, Efthimiadis $\mathrm{A}$, Hargreave FE. Occupational eosinophilic bronchitis without asthma: an unknown occupational airway disease. J Allergy Clin Immunol 1997; 100: 852-853.

12. Wong AG, Pavord ID, Sears MR, Hargreave FE. A case for serial examination of sputum inflammatory cells. Eur Respir $J$ 1996; 9: 2174-2175. 